\title{
Effect of the Addiction of Metal Oxide Nanoparticles on the Physical, Chemical and Thermal Properties of PVA Based Nanocomposites
}

\author{
Raquel Couto de Azevedo Gonçalves Mota*, Emerson Oliveira da Silva, \\ Lívia Rodrigues de Menezes \\ Instituto de Macromoléculas Professora Eloisa Mano, Universidade Federal do Rio de Janeiro, Rio de Janeiro, Brazil \\ Email: *raquel@nano.ufrj.br
}

How to cite this paper: Mota, R.C.A.G., da Silva, E.O. and de Menezes, L.R. (2018) Effect of the Addiction of Metal Oxide Nanoparticles on the Physical, Chemical and Thermal Properties of PVA Based Nanocomposites. Materials Sciences and Applications, 9, 473-488.

https://doi.org/10.4236/msa.2018.95033

Received: March 18, 2018

Accepted: May 19, 2018

Published: May 22, 2018

Copyright $\odot 2018$ by authors and Scientific Research Publishing Inc. This work is licensed under the Creative Commons Attribution International License (CC BY 4.0).

http://creativecommons.org/licenses/by/4.0/

\begin{abstract}
In this study, poly(vinyl alcohol) (PVA)-based nanocomposites consisting of metallic oxide nanoparticles $\left(\mathrm{TiO}_{2}, \mathrm{ZnO}, \mathrm{ZrO}_{2}\right)$ were obtained from an aqueous solution of $7 \% \mathrm{PVA}$, in order to compare the microstructural, and physical properties of bionanocomposite films reinforced with various loading contents $(0.1 \%, 0.2 \%$ and $0.3 \% \mathrm{w} / \mathrm{w})$. They were evaluated regarding their molecular toughness through Nuclear Magnetic Resonance (NMR), regarding their chemical structural through Fourier Transform Infrared Spectroscopy (FTIR), regarding their crystallinity throught X-ray Diffraction (XRD), and regarding termal properties through Thermogravimetric Analysis (TGA) and Differential Scanning Calorimetry (DSC). The NMR results showed that the smallest concentrations of these oxides have a tendency to disperse better in the polymeric matrix, improving the structural toughness. Besides, changes in the termal resistance of the material were found with the use of TGA and DSC.
\end{abstract}

\section{Keywords}

Poly(vinyl alcohol), Nanocomposites, Metallic Oxides, Titanium Oxide, Zirconium Oxide, Zinc Oxide

\section{Introduction}

Polyvinyl alcohol (PVA) is a biocompatible, biodegradable and non-toxic water-soluble polymer [1]. It was obtained for the first time in 1924, by Herrman 
and Haehnel, through the hydrolysis of polyvinyl acetate, since the corresponding monomer "vinyl alcohol" does not exist in free state. In 1961, Staudinger researched the reversible transformation between polyvinyl alcohol and polyvinyl acetate through the reactions of esterification and saponification [2]. The quantity of hydrolysis determines the physical, chemical and mechanical properties. With more hydroxylation, the less it will be soluble in water and the harder its crystallization will be [3].

This polymer is an excellent adhesive, has good organic solvent resistance and its resistance to oxygen passage is superior to that of any other known polymer. It is one of the few water-soluble semicrystalline polymers with good interfacial characteristics. It is widely used in the textile industry, in the packaging industry and in biomedical applications such as contact lenses, medication, orthopedic materials, tissue engineering and the manufacturing of artificial organs [1].

Zirconia $\left(\mathrm{ZrO}_{2}\right)$ is a ceramic widely spread in the planet and also present in the human body, in bone tissue, in amounts ranging from $2-20 \mathrm{mg} / \mathrm{kg}$ [4]. Due to its versatility, it has been used as a biomedical material since 1970. It can be found in the polymorphic forms monoclinic, tetragonal and cubic. It is a biocompatible and bioactive material, capable of inducing cell adhesion, differentiation and proliferation, contributing to a better osseointegration. Besides, when under stress, its metastable tetragonal phase transforms into the polymorphic monoclinic, closing around the crack, which causes an expansion of the volume and the compressive stress and stops the crack from propagating.

Zirconia has been introduced as coating to metallic or polymeric implants due to its physical properties. In 2010, Liu et al. has deposited thin zirconia films and managed not just a great deposition of hydroxyapatite via simulated body fluid (SBF) but also great mesenchymal cell adherence and proliferation [5].

Titania $\left(\mathrm{TiO}_{2}\right)$, in turn, is an organic ceramic material that presents three crystal structures: Anatase (tetragonal), rutile (tetragonal) and brookite (orthorhombic), [6] but the brookite form is unstable, difficult to synthesize, and is not very interesting, while rutile and anatase are more widely researched, can be synthesized in laboratories and are semiconductors, showing catalytic activity. [6]

Titanium oxides are widely utilized in tissue engineering due to its non-toxicity, low cost, photocatalytic activity, but mostly due to its bactericide properties, which have been studied and reported in many papers. Haldorai et al. (2016) has created chitosan nanohybrids with $\mathrm{TiO}_{2}$ to test its bactericide action against E. Coli and had positive results. [7]

Zinc Oxide $(\mathrm{ZnO})$ is a polymorphic semiconductive material that can be found in the following forms: wurtzite (hexagonal), zinc blend (cubic) and rocksalt (cubic), but only wurtzite is thermodynamically stable in ambient conditions. This material presents good chemical compatibility and stability, bactericide and fungicide action and can be non-toxic in vitro and in vivo. These characteristics make zinc oxide very attractive to the biomedical field, being used in cosmetics, drugs, orthopedic materials, scaffolds and bioimaging. Besides, zinc 
oxide is biodegradable; $\mathrm{Zn}^{+2}$ is an indispensable element in the human body, taking part in many steps in the adult metabolism [8].

Since nanometric zinc oxide exhibits fluorescence, it has been widely utilized in pre-clinical researches, as it is cheap and convenient. Hong et al., in a previous study (2011), have synthesized $\mathrm{ZnO}$ nanowires for cancer cells imaging, using av $\beta 3$ integrin antagonist as linkers. Besides that, the isotope ${ }^{64} \mathrm{Cu}(1 / 2 \mathrm{t}=12.7 \mathrm{~h})$ has been added to evaluate the biodistribution in mice. The nanowires accumulated in the reticuloendothelial system and degraded, being eliminated of the mice's bodies [9].

The aim of this work was to evaluation the effect of addition and concentration of metallic oxides (titanium oxide, zinc oxide and Zirconium oxide) on the thermal properties, crystallinity and molecular dynamic of a poly(vinyl alcohol) matrix.

\section{Experimental Section}

\subsection{Materials}

For this paper, the following materials have been used:

- Polyvinyl alcohol, acquired from VETEC (Química Fina) with a hydrolysis level between $86.5 \%$ and $89.5 \%$;

- Titanium oxide acquired from Sigma Aldrich containing a particle size about $100 \mathrm{~nm}$;

- Zinc oxide acquired from Sigma Aldrich containing a particle size about to $100 \mathrm{~nm}$;

- Zirconium oxide acquired from Sigma Aldrich containing a particle size about to $100 \mathrm{~nm}$.

\subsection{Methodology}

The PVA nanocomposites were obtained through aqueous solution with three different oxides (zinc oxide, zirconium oxide and titanium oxide) with the concentration of $0.1 \%$ and $0.2 \% \mathrm{~m} / \mathrm{m}$, according to Table 1 . For that effect, the $88 \%$ hydrolyzed PVA was solubilized in half of the water volume needed to obtain $7 \%$ $\mathrm{m} / \mathrm{v}$ systems and kept in magnetic stirring for $1.5 \mathrm{~h}$ at $80^{\circ} \mathrm{C}$. After this stage, the solutions were left to rest for $24 \mathrm{~h}$. The concentrations and the prepration method were chosen based on previous knowledge the authors acquired working with the polymer and the nanoparticles.

After the $24 \mathrm{~h}$, the nanoparticles of each group were added to the other half of the deionized water and dispersed by introducing an ultrasound tip at $99 \%$ power for one minute, applying intensity 3 pulses every 15 seconds. Then the nanoparticles suspension was verted in the PVA solutions and those were kept stirring at room temperature for $1.5 \mathrm{~h}$.

Once the films of each group had been obtained, they were poured into plastic petri dishes and placed into an incubator at $60^{\circ} \mathrm{C}$ for 4 days to completely remove the solvent. After that was done, these systems were analyzed with the following 
Table 1. PVA systems/oxides obtained.

\begin{tabular}{ccc}
\hline Sample's nomenclature & $\begin{array}{c}\text { Nanoparticle dispersed in } \\
\text { the PVA matrix }\end{array}$ & $\begin{array}{c}\text { \% of nanoparticles } \\
(\mathrm{m} / \mathrm{m})\end{array}$ \\
\hline Pure PVA & - & - \\
$\mathrm{PVA}+0.1 \% \mathrm{TiO}_{2}$ & Titanium oxide $\left(\mathrm{TiO}_{2}\right)$ & 0.1 \\
$\mathrm{PVA}+0.1 \% \mathrm{ZrO}_{2}$ & Zirconium oxide $\left(\mathrm{ZrO}_{2}\right)$ & 0.1 \\
$\mathrm{PVA}+0.1 \% \mathrm{ZnO}$ & Zinc oxide $(\mathrm{ZnO})$ & 0.1 \\
$\mathrm{PVA}+0.2 \% \mathrm{TiO}_{2}$ & Titanium oxide $\left(\mathrm{TiO}_{2}\right)$ & 0.2 \\
$\mathrm{PVA}+0.2 \% \mathrm{ZrO}_{2}$ & Zirconium oxide $\left(\mathrm{ZrO}_{2}\right)$ & 0.2 \\
$\mathrm{PVA}+0.2 \% \mathrm{ZnO}_{\mathrm{PVA}}+0.3 \% \mathrm{TiO}_{2}$ & Zinc oxide $(\mathrm{ZnO})$ & 0.2 \\
$\mathrm{PVA}+0.3 \% \mathrm{ZrO}_{2}$ & Titanium oxide $\left(\mathrm{TiO}_{2}\right)$ & 0.3 \\
$\mathrm{PVA}+0.3 \% \mathrm{ZnO}$ & Zirconium oxide $\left(\mathrm{ZrO}_{2}\right)$ & 0.3 \\
\hline
\end{tabular}

techniques: X-ray diffraction, thermogravimetric analysis, Fourier transform infrared spectroscopy, time-domain nuclear magnetic resonance, evaluation of calcium deposition, with the intent of determining which particles and concentrations showed the most promise between the chosen oxides.

\subsection{Characterization}

\subsubsection{Fourier Transform Infrared Spectroscopy (FTIR)}

The FTIR analysis were performed in the wavenumber range $400 \mathrm{~cm}^{-1}$ to 4000 $\mathrm{cm}^{-1}$, to evaluate the possibility of nanoparticle interaction with the coating polymer and, later, to keep track of the hydroxyapatite deposition in these structures by having trials in body fluid. For such, the scaffolds were analyzed at $25^{\circ} \mathrm{C}$.

\subsubsection{X-Ray Diffraction (XRD)}

The XRD technique was used to verify the structural modifications caused by the addition of the particles in the PVA matrix. Diffractograms were obtained using the X-ray diffractometer at $40 \mathrm{kV}$ and $30 \mathrm{~mA}, 0.05^{\circ} / \mathrm{s}$, in room temperature. $\mathrm{CuKa}$ radiation was the source of the X-rays, with $0.15418 \mathrm{~nm}$ wavelength and analysis interval of $2 \theta=2^{\circ}$ at $60^{\circ}$. After getting the diffractograms, the crystallinity of the PVA-based systems was determined through the Ruland method [10].

\subsubsection{Thermogravimetric Analysis (TGA)}

Thermogravimetric analysis was used to limit the analysis range of the DSC. TGA measurements were obtained with the TGA Q500 Thermogravimetric Analyzer (TA Instruments) in an interval from $40^{\circ} \mathrm{C}$ to $700^{\circ} \mathrm{C}$ and heating rate of $10^{\circ} \mathrm{C} / \mathrm{min}$ under $\mathrm{N}_{2}$ flow of $50 \mathrm{~mL} / \mathrm{min}$.

\subsubsection{Differential Scanning Calorimetry (DSC)}

The analyses were run in TA-Instruments Q.1000 equipment under $\mathrm{N}_{2}$ flow of $50 \mathrm{~mL} / \mathrm{min}$, with heating rate of $5^{\circ} \mathrm{C} / \mathrm{min}$, between $0^{\circ} \mathrm{C}$ and $200^{\circ} \mathrm{C}$. For these 
analysis, an analytic balance was used to measure out $10 \mathrm{mg}( \pm 0.2 \mathrm{mg})$ of each of the coated scaffolds.

The crystallinity $\left(X_{c}\right)$ of the nanocomposites was calculated with Equation (1), by obtaining crystallization enthalpy $\left(\Delta H_{\mathrm{c}}\right)$, heat of fusion $\left(\Delta H_{\mathrm{f}}\right)$ and through heat of fusion of $100 \%$ crystalline PVA, $\Delta H_{\mathrm{f} 100 \%}=138.60 \mathrm{~J} / \mathrm{g}$ [11]. PLA was chosen for this analysis because it is the predominant compound in the scaffold, while the coating only represented $2 \%$ of the system, and for that reason, can be ignored in this analysis.

$$
X_{c}(\%)=\frac{\Delta H_{f}-\sum \Delta H_{c}}{W_{\mathrm{PLA}} \times \Delta H_{f 100 \%}} \times 100
$$

where,

$X_{\mathrm{c}}(\%)=$ degree of crystallinity;

$\Delta H_{f}=$ heat fusion of PLA in the sample, in $\mathrm{J} / \mathrm{g}$;

$\Delta H_{f 100 \%}=$ heat fusion of hypothetically $100 \%$ crystalline PLA, in J/g;

$\Delta H_{c}=$ crystallization enthalpy of PLA in the sample, in $\mathrm{J} / \mathrm{g}$;

$W_{\text {PLA }}=$ PLA fraction in the sample obtained by the average of the TGA analysis, in \%.

The enthalpy and temperature values were obtained with TA7000 software and the graphics were generated by the Origin 8.0 software.

\subsubsection{Time-Domain Nuclear Magnetic Resonance Relaxometry (TD-NMR)}

The time-domain NMR analyses were achieved through the definition of longitudinal spin-lattice relaxation time $\left(T_{1} H\right)$, measured with the inversion-recovery pulse sequence in the NMR Resonance Maran Ultra $0.54 \mathrm{~T}$ equipment for low field NMR. The samples were placed in an $18 \mathrm{~mm}$ tube, which was placed in the probe. The frequency of the ${ }^{1} \mathrm{H}$ nuclei being observed was $23 \mathrm{MHz}$ and the interval bandwidth of the waiting time between pulses $\mathrm{p} 180 \mathrm{x}-\tau-\mathrm{p} 90 \mathrm{x}$ and it varied between $0.01-10,000 \mathrm{~ms}$ with recycle interval of $3 \mathrm{~s}$.

The relaxometry analysis of the systems had the main goal of evaluating the molecular dynamics of the systems obtained with the intention of establishing which of the systems had the best dispersion of nanoparticles in scaffold coating.

\section{Results and Discussion}

\subsection{Fourier Transform Infrared Spectroscopy (FTIR)}

PVA's FTIR shows all the characteristic wavelengths of this polymer, as demonstrated in Table 2. Based on the FTIR spectra obtained for pure PVA and for each of its nanocomposites (Figures 1-3), one can determine that there was no change in the positioning or the shape of the wavelength regarding the PVA matrix. This behavior shows that the interaction between the polymeric matrix and the nanoparticles possibly prevails in a physical manner, or that the chemical interaction between the phases happens through low intensity forces, that this technique cannot detect. 
Table 2. Assignment of infrared wavelengths to PVA.

\begin{tabular}{cc}
\hline Sample & Wavelength $\left(\mathrm{cm}^{-1}\right)$ \\
\hline $\mathrm{O}-\mathrm{H}$ & 3450 \\
$\mathrm{C}-\mathrm{H}$ & 2930 \\
$\mathrm{C} \equiv \mathrm{C}$ & 2050 \\
Uunsaturated aldehyde or ketone & 1705 \\
$\mathrm{C}=\mathrm{C}$ & 1640 \\
$\mathrm{C} \equiv \mathrm{C}$ conjugate & 1585 \\
$-\mathrm{CH}-$ & 1450 \\
$-\mathrm{C}-\mathrm{O}-\mathrm{H}-$ & 1080 \\
\hline
\end{tabular}

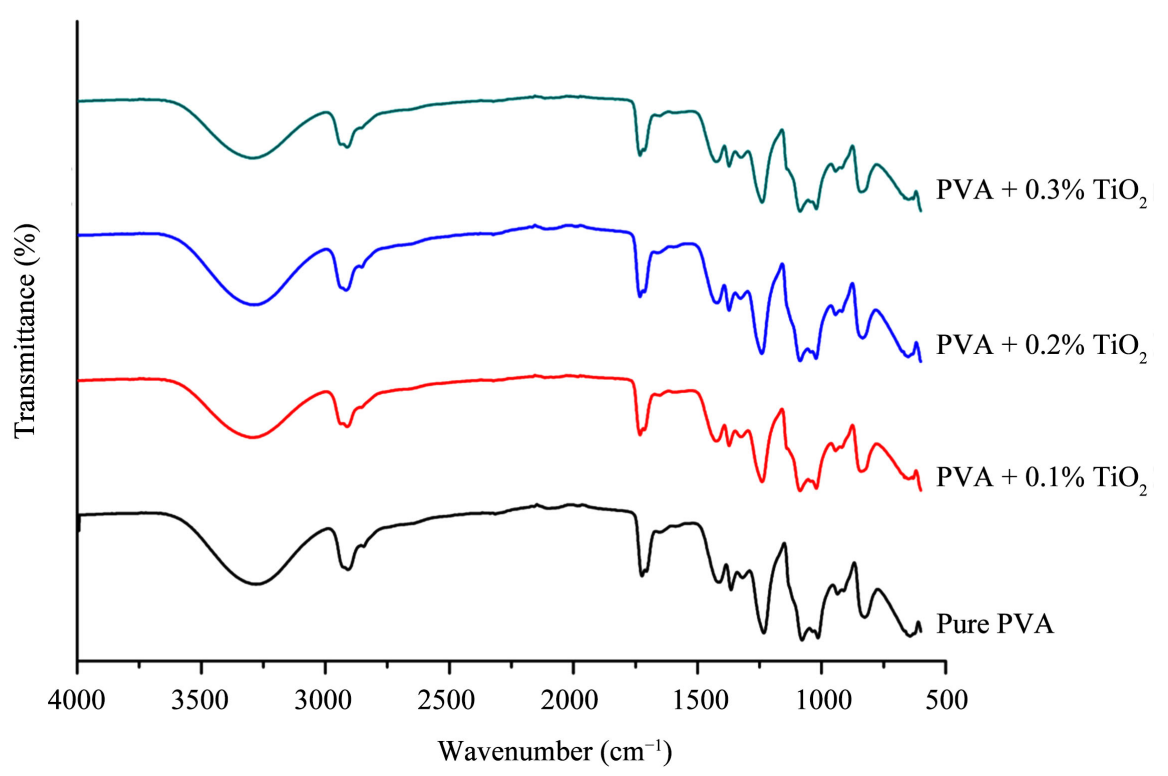

Figure 1. FTIR of PVA nanocomposites with titanium oxide.

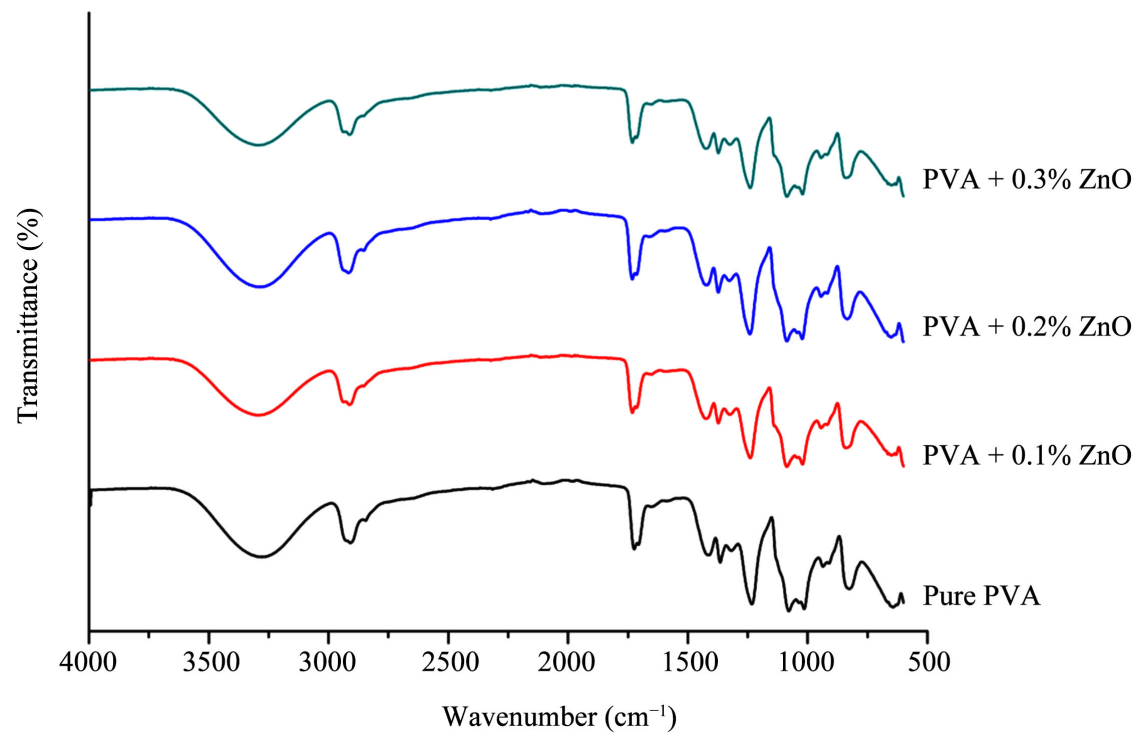

Figure 2. FTIR of PVA nanocomposites with zinc oxide. 


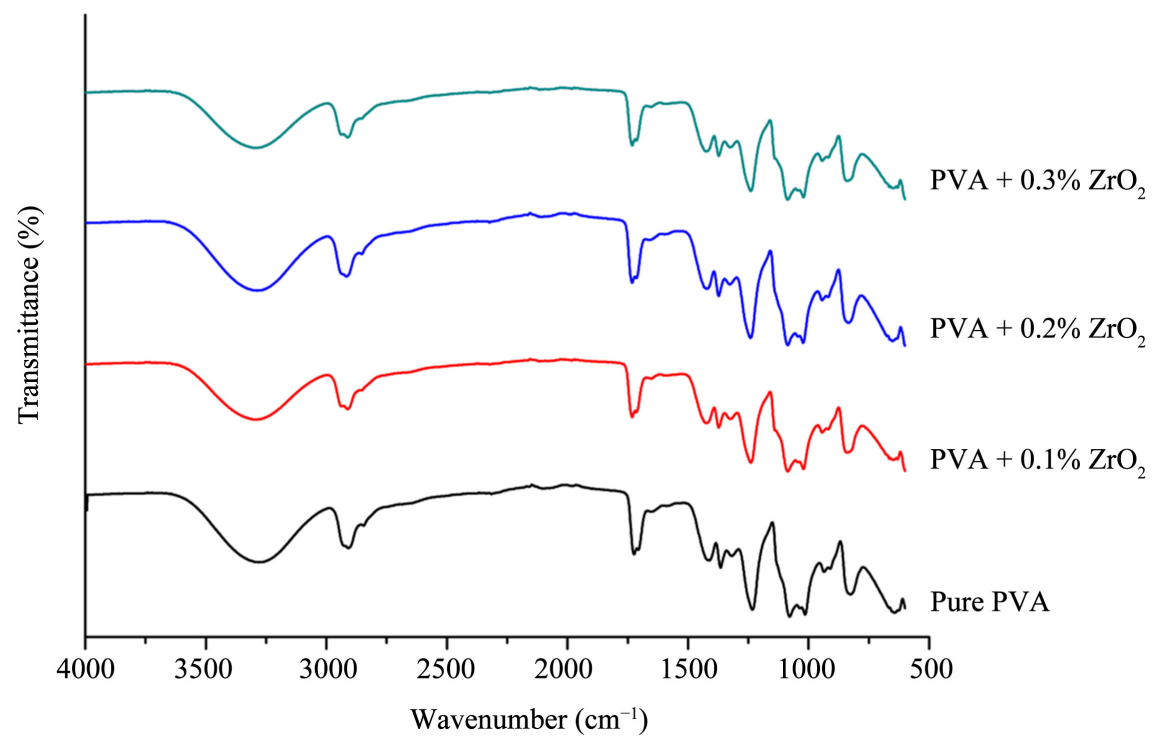

Figure 3. FTIR of PVA nanocomposites with zirconium oxide.

However, it must be noted that another possibility for the lack of variation of the wavelengths is that, in this study, the metallic oxides particles were used at reduced concentrations $(0.1 \%, 0.2 \%$ and $0.3 \%)$. The low concentration of these oxides in the systems could be below the equipment's detection limits.

\subsection{Ray Diffraction (XRD)}

The PVA diffraction pattern was analyzed based on the monoclinic structure for the unit cell $\left(\mathrm{a}=0.781 \mathrm{~nm} ; \mathrm{b}=0.252 \mathrm{~nm} ; \mathrm{c}=0.551 \mathrm{~nm}\right.$ e $\left.\beta=91,42^{\circ}\right)$ described by BUNN (1948) and later reported in many different studies [12] [13].

The films were analyzed through XRD with the intent of evaluating the effect of nanostructure insertion over the polymeric matrix (Figures 4-6). Based on the results of pure polymer, one can notice that it has two crystalline peaks, which characterizes a low crystallinity system, centered at approximately $2 \theta=$ $19.5^{\circ}$, e $2 \theta=40.8^{\circ}$ and a less intense shoulder at $22.2^{\circ}$. This diffractogram profile shows the typical presence of a semi-crystalline structure and is similar to other results previously described in the literature, for its mostly atactic, which is reflected in its low crystallinity degree (Table 3 ).

The nanocomposite systems, both the $0.1 \%, 0.2 \%$ and $0.3 \%$, presented the same behavior as the pure polymer, showing the same peaks, with similar intensity and width between them. However, it is possible to observe that the addition of nanocharge provokes a shift of the peak centered at $2 \theta=20.04^{\circ}$. The $0.1 \%$ concentration made this peak shift towards narrower angles, while $0.2 \%$ and $0.3 \%$ made it shift towards wider angles, which indicates that the presence of these particles could alter PVA's crystal planes.

In the first case $(0.1 \%)$, when the particles were inserted in the polymeric matrix, they may have acted as a nucleating agent, favoring the structural organization of the polymer, which leads to the generation of a larger number of smaller-sized crystals. 


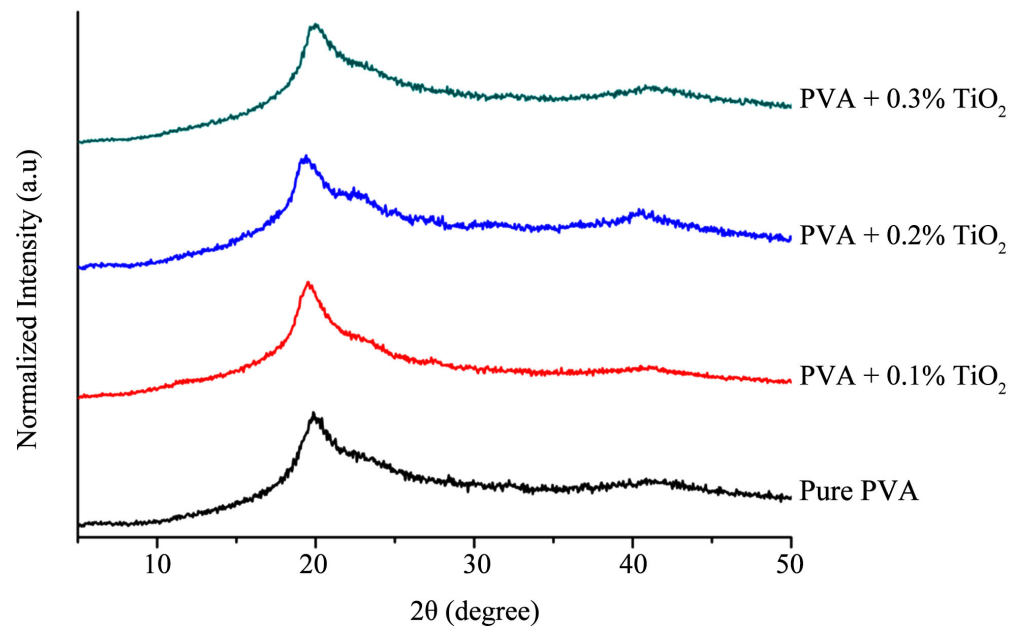

Figure 4. XRD of the PVA nanocomposites with titanium oxide, compared to the pure PVA film.

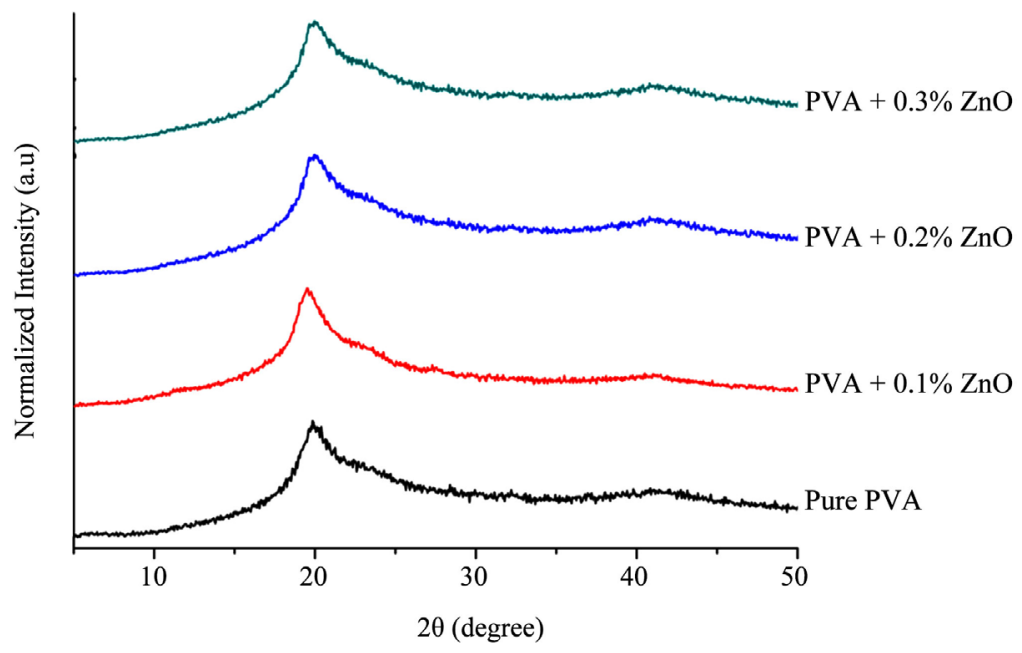

Figure 5. XRD of the PVA nanocomposites with zinc oxide, compared to the pure PVA film.

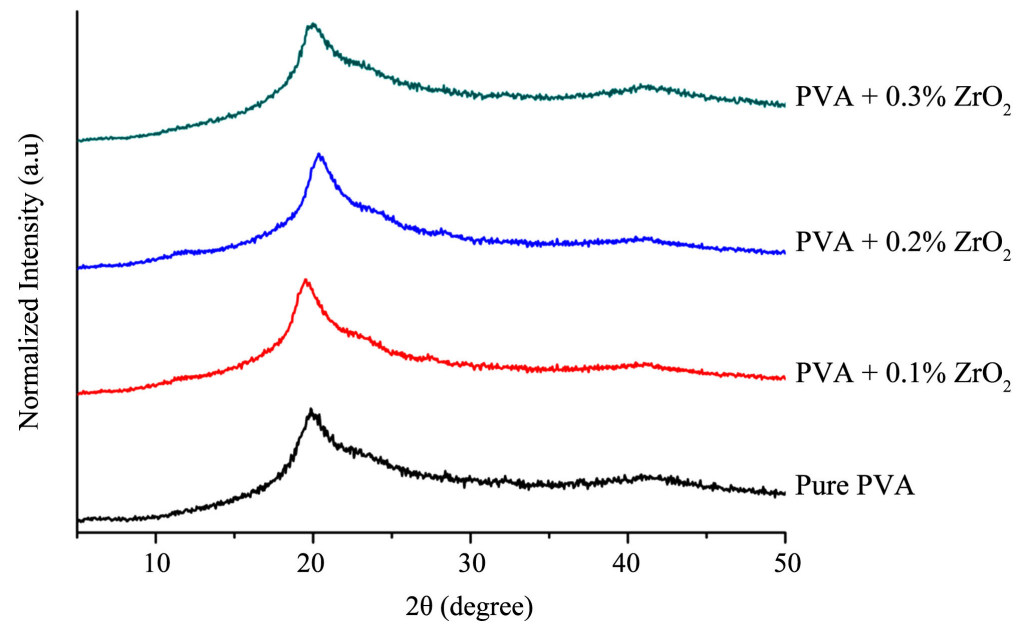

Figure 6. XRD of the PVA nanocomposites with zirconium oxide, compared to the pure PVA film. 
Table 3. Crystallinity degree of the samples based in diffractograms.

\begin{tabular}{ccc}
\hline Sample & $\boldsymbol{X}_{\mathrm{c}}(\%)$ & $2 \boldsymbol{2}$ \\
\hline Pure PVA & 11 & $20.0^{\circ}$ \\
$\mathrm{PVA}+0.1 \% \mathrm{TiO}_{2}$ & 16 & $19.7^{\circ}$ \\
$\mathrm{PVA}+0.2 \% \mathrm{TiO}_{2}$ & 9 & $20.7^{\circ}$ \\
$\mathrm{PVA}+0.3 \% \mathrm{TiO}_{2}$ & 9 & $20.6^{\circ}$ \\
$\mathrm{PVA}+0.1 \% \mathrm{ZnO}$ & 12 & $19.3^{\circ}$ \\
$\mathrm{PVA}+0.2 \% \mathrm{ZnO}$ & 10 & $20.4^{\circ}$ \\
$\mathrm{PVA}+0.3 \% \mathrm{ZnO}$ & 10 & $20.4^{\circ}$ \\
$\mathrm{PVA}+0.1 \% \mathrm{ZrO}_{2}$ & 14 & $19.7^{\circ}$ \\
$\mathrm{PVA}+0.2 \% \mathrm{ZrO}_{2}$ & 8 & $20.4^{\circ}$ \\
$\mathrm{PVA}+0.3 \% \mathrm{ZrO}_{2}$ & 9 & $20.5^{\circ}$ \\
\hline
\end{tabular}

However, when the nanoparticles were inserted in the polymeric matrix at a highers concentrations $(0.2 \%$ and $0.3 \%)$, the $2 \theta$ values increased, which indicated the generation of bigger-sized crystals, which may have been caused by badly dispersed nanocharges in the polymeric matrix, hurting the interaction between the nanostructures and the PVA, forming clusters. This way, the nanoparticles possibly increase the distance between the crystalline lamellae due to the inclusion of small agglomerates of charge between the crystalline structure of the PVA. This effect has been previously observed by Hemalatha et al., (2014), while dispersing $\mathrm{ZnO}$ nanoparticles, in high concentrations, between $5 \%$ and $20 \%$, in a PVA matrix [14].

Regarding the crystallinity degree of the systems, one can determine that the addition of the oxides at the $0.1 \%$ concentration has led the crystallinity degree to increase, which is interconnected with the possible nucleating action of these nanoparticles. On the other hand, the addition of these particles at the $0.2 \%$ and $0.3 \%$ concentration has decreased the PVA's crystallinity, possibly due to its agglomeration, which led to the generation of clusters which can physically come in the way of the organization of the chains [15] [16]. Ahmad et al. (2014) reported a similar effect in their systems. They evaluated that, when $\mathrm{TiO}_{2}$ concentration is high, the nanoparticles interfere and hinder the polymer chains packing, which causes a decrease in the nanocomposites crystallinity [17].

\subsection{Thermogravimetric Analysis (TGA)}

This analysis was made as a way of measuring the influence of incorporating the metallic oxides over the thermal stability of the material. The thermograms are shown in the images pictured below (Figures 7-9).

Based on these results, it can be said that the PVA matrix's degradation presents three main weight loss events, as described in the literature [18].The first of them occurs at around $100^{\circ} \mathrm{C}$ and is related to the remaining water leaving the system. Most of the weight loss takes place at around $300^{\circ} \mathrm{C}$, due to the 


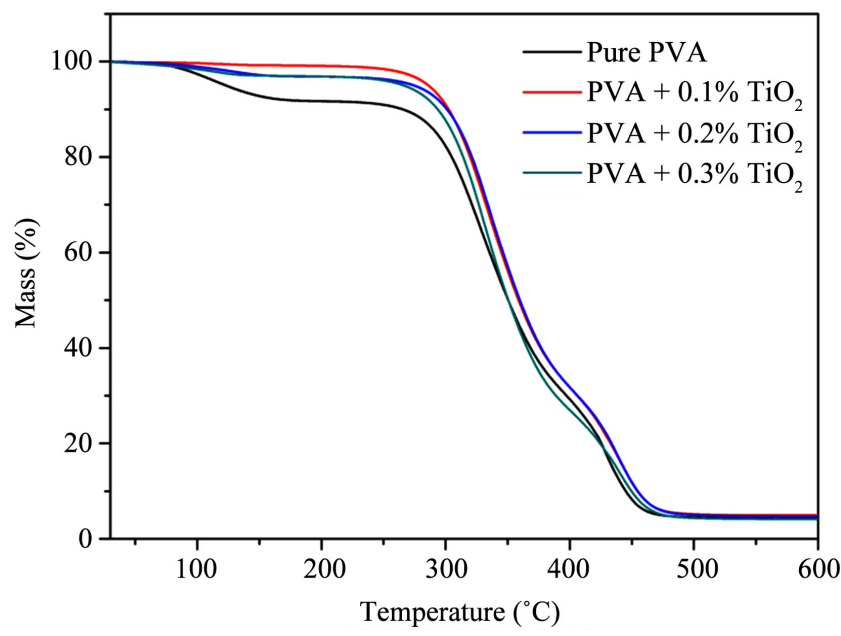

Figure 7. TGA of the PVA nanocomposites with titanium oxide, compared to the pure PVA film.

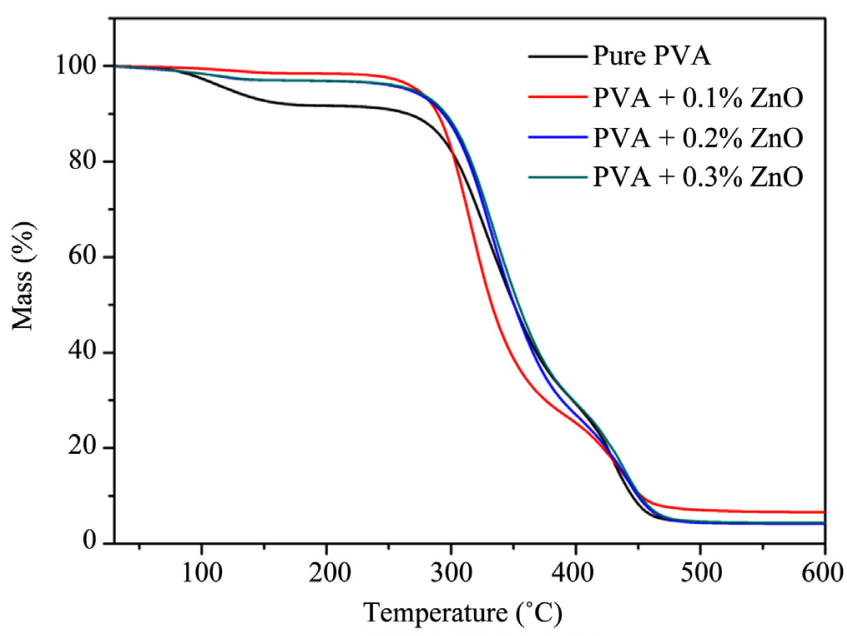

Figure 8. TGA of the PVA nanocomposites with zinc oxide, compared to the pure PVA film.

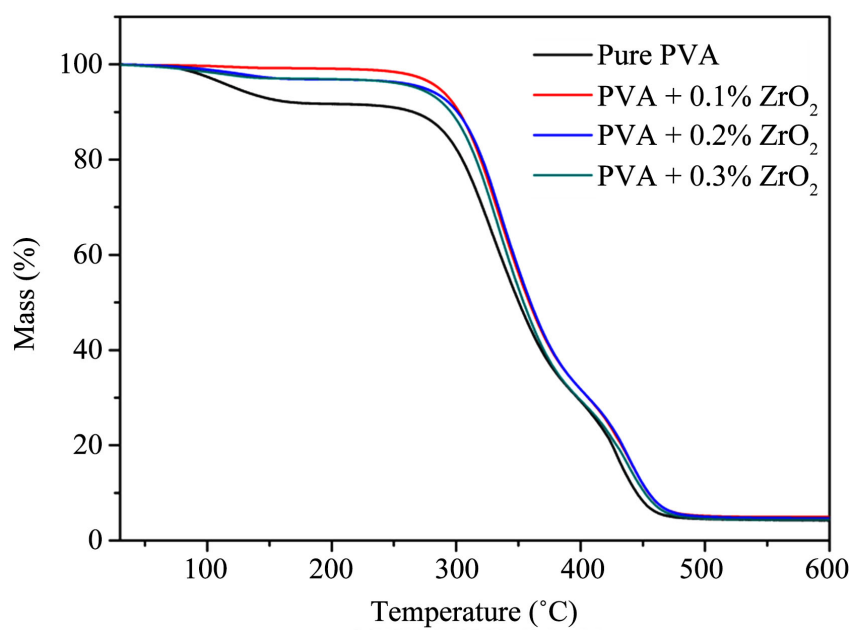

Figure 9. TGA of the PVA nanocomposites with zirconium oxide, compared to the pure PVA film. 
exit of the lateral group acetate, followed by a third loss between $350^{\circ} \mathrm{C}$ and $450^{\circ} \mathrm{C}$, which correlates to a proper PVA polymeric network degradation rate [13]. The second weight loss was considered to be the temperature where real degradation started for the onset temperature evaluation, because it corresponds to the moment when there is in fact degradation of the polymeric matrix (Table $4)$.

The results for the nanocomposites shown in Table 4 indicate that the presence of the oxides in the PVA matrix was not able to change the thermal resistance of the obtained systems regarding the thermal resistance of the material, once the $\mathrm{T}_{\text {onset }}$ values of all the samples was sustained, at a value of approximately $\mathrm{T}_{\text {onset }}=301^{\circ} \mathrm{C} \pm 2^{\circ} \mathrm{C}$. Similarly, there was no difference in $\mathrm{T}_{\text {peak }}$ values between pure PVA films and the nanocomposites. However, when observing the thermograms shown above, it is possible to highlight that the presence of these nanoparticles has largely affected the amount of water that was adsorbed or retained by the systems.

The results obtained in this paper contradict most of the studied papers [15] [17] [19] [20] [21] [22], which show that incorporating nanoparticles in the polymeric matrix causes an increase in the thermal stability of the material, for it decreases its molecular mobility and limits the gas flow during the degradation process. Nevertheless, the behavior shown can be attributed to the nature of the particles studied, once the metallic atoms in these particles can act as degradation accelerators in some of these matrices [20] [23] [24] [25].

\subsection{Differential Scanning Calorimetry (DSC)}

The Differential Scanning Calorimetry (DSC) analysis were run for the nanocomposite films to find out the values of their glass transition temperature $\left(T_{\mathrm{g}}\right)$, melting point $\left(\mathrm{T}_{\mathrm{m}}\right)$ and to calculate their degree of crystallinity $\left(X_{\mathrm{c}}\right)$ to determine how much the addition of the metallic oxides influenced the thermal transitions of the polymeric. The results are shown in Table 5, located below.

It is possible to notice, when examining the crystallinity degree, a tendency that corroborates the XDR results. The lower concentration (0.1\%) increases the $\mathrm{X}_{c}$, while the higher concentrations $(0.2 \%$ and $0.3 \%)$ cause a reduction. This behavior can be explained by the dispersion of the nanoparticles in the polymeric matrix. The $0.1 \%$ concentration has good dispersion, and, for that reason, the nanoparticles act as nucleating agents, helping with the crystallinity of the material. In the higher concentration systems there may have been the formation of clusters, which impairs the growth of the crystals and reduces the final crystallinity, as reported in several other papers [24] [25]. Xu et al. (2017) observed similar results; an increase in the crystallinity of PVA with addition of the lower concentrations of $\mathrm{TiO}_{2}$, and a decrease with the higher concentrations. He explains that when nanoparticles are well dispersed, hydrogen bonds form and therefore the crystallinity increases. When the concentrations are higher, these hydrogen bonds are damaged, which has a negative impact in the crystallinity [25]. 
Table 4. TGA parameters of the nanocomposite films.

\begin{tabular}{ccc}
\hline Sample & $\mathrm{T}_{\text {onset }}\left({ }^{\circ} \mathrm{C}\right)$ & $\mathrm{T}_{\text {peak }}\left({ }^{\circ} \mathrm{C}\right)$ \\
\hline $\mathrm{PVA}$ & 301 & $334 / 440$ \\
$\mathrm{PVA}+0.1 \% \mathrm{TiO}_{2}$ & 301 & $333 / 440$ \\
$\mathrm{PVA}+0.2 \% \mathrm{TiO}_{2}$ & 302 & $335 / 441$ \\
$\mathrm{PVA}+0.3 \% \mathrm{TIO}_{2}$ & 301 & $333 / 441$ \\
$\mathrm{PVA}+0.1 \% \mathrm{ZnO}$ & 302 & $333 / 442$ \\
$\mathrm{PVA}+0.2 \% \mathrm{ZnO}$ & 299 & $333 / 440$ \\
$\mathrm{PVA}+0.3 \% \mathrm{ZnO}^{\mathrm{P} O}+0.1 \% \mathrm{ZrO}_{2}$ & 300 & $333 / 440$ \\
$\mathrm{PVA}+0.2 \% \mathrm{ZrO}_{2}$ & 300 & $334 / 441$ \\
$\mathrm{PVA}+0.3 \% \mathrm{ZrO}_{2}$ & 299 & $333 / 439$ \\
\hline
\end{tabular}

Table 5. Thermical parameters (Tg, Tm) and crystallinity of PVA systems.

\begin{tabular}{|c|c|c|c|c|}
\hline Sample & $\mathrm{T}_{\mathrm{g}}\left({ }^{\circ} \mathrm{C}\right)$ & $\mathrm{T}_{\mathrm{m}}\left({ }^{\circ} \mathrm{C}\right)$ & $\Delta \mathrm{H}_{\mathrm{f}}(\mathrm{J} / \mathrm{g})$ & $\mathrm{X}_{\mathrm{c}}(\%)$ \\
\hline PVA & 48 & 182 & 17.4 & 13 \\
\hline $\mathrm{PVA}+0.1 \% \mathrm{TiO}_{2}$ & 50 & 183 & 25.7 & 18 \\
\hline $\mathrm{PVA}+0.2 \% \mathrm{TiO}_{2}$ & 50 & 182 & 15.1 & 11 \\
\hline $\mathrm{PVA}+0.3 \% \mathrm{TIO}_{2}$ & 48 & 182 & 15.9 & 11 \\
\hline $\mathrm{PVA}+0.1 \% \mathrm{ZnO}$ & 51 & 180 & 19.6 & 14 \\
\hline $\mathrm{PVA}+0.2 \% \mathrm{ZnO}$ & 47 & 182 & 16.5 & 12 \\
\hline $\mathrm{PVA}+0.3 \% \mathrm{ZnO}$ & 48 & 182 & 15.8 & 11 \\
\hline $\mathrm{PVA}+0.1 \% \mathrm{ZrO}_{2}$ & 56 & 183 & 22.2 & 16 \\
\hline $\mathrm{PVA}+0.2 \% \mathrm{ZrO}_{2}$ & 54 & 183 & 15.3 & 11 \\
\hline $\mathrm{PVA}+0.3 \% \mathrm{ZrO}_{2}$ & 54 & 182 & 16.4 & 12 \\
\hline
\end{tabular}

The increase of the glass transition temperature can also be explained by the addition of the metallic oxides, which are rigid nanoparticles, to the polymeric matrix, because they make its relaxation harder in the amorphous phase. For that reason, all of the systems show a higher $\mathrm{T}_{\mathrm{g}}$ when compared to that of the pure polymer. One would assume that the higher nanoparticles levels would also increase the rigid phase, decrease mobility and consequently decrease the $\mathrm{T}_{\mathrm{g}}$. However, that does not happen. The lower concentration $(0.1 \%)$ has a more significant increase than the other two $(0.2 \%$ and $0.3 \%)$.

The dispersion of the nanoparticles also influences the $\mathrm{T}_{\mathrm{g}} \mathrm{s}$, since they show a larger interaction area with the polymer when well-dispersed in the matrix, which compromised the mobility of the polymeric chains. When the nanoparticles are badly dispersed they tend to form clusters, which would explain why the $T_{g}$ increase doesn't surpass that of the lower concentrations. 


\subsection{Time-Domain Nuclear Magnetic Ressonance (NMR)}

The study of time-domain nuclear magnetic resonance Relaxometry was done with the intent of evaluating the molecular dynamics of the PVA-based nanocomposites with zinc oxide, zirconium oxide and titanium oxide. After this trial, the relaxation time $\left(\mathrm{T}_{1} \mathrm{H}\right)$ after exponential decay (Table 6) was calculated, and the relaxation curves were obtained.

Figure 10 show that the nanoparticle concentrations $(0.1 \%, 0.2 \%$ and $0.3 \%)$ alter the relaxation time $\mathrm{T}_{1} \mathrm{H}$ when compared to the pure PVA coating, but their effects are opposite. The lower concentration of $\mathrm{TiO}_{2}$ and $\mathrm{ZnO}$ increased the relaxation time, while the highest concentration reduced it.

In the first case $(0.1 \%)$, when the nanoparticles were inserted into the polymeric matrix, they culminated in a higher $\mathrm{T}_{1} \mathrm{H}$ value, which translates into an increase of the molecular rigidity of the material, since the nanoparticles can disperse better in the polymer, managing thus a better interaction between nanostructure and polymeric matrix.

When the nanoparticles were inserted in the polymeric matrix at a higher concentration $(0.2 \%$ and $0.3 \%)$, the $\mathrm{T}_{1} \mathrm{H}$ values dropped due to the agglomeration of nanoparticles, which formed a cluster, and that may have caused the phases to separate. That separation provokes an increased the distance between polymeric chains and increased free volume, which leads to an increase in molecular mobility. This explains how the increase of nanoparticles makes the relaxation time shorter, also described in the literature [25] [26].

Zirconia, however, shows an effect different from that of the other nanoparticles, since it alters both the relaxation time and the width of the curve. All $\mathrm{ZrO}_{2}$ concentrations increase the relaxation time due to the fact that zirconia is an extremely rigid particle that, when added to a polymeric matrix, makes its relaxation more difficult. The smallest concentration of $\mathrm{ZrO}_{2}$ shows the highest $\mathrm{T}_{1} \mathrm{H}$ due to its better dispersion.

Table 6. Spin-lattice relaxation time of the PVA/metallic oxides systems.

\begin{tabular}{cc}
\hline Sample & $\mathrm{T}_{1} \mathrm{H}(\mathrm{ms})$ \\
\hline Pure PVA & 312 \\
$\mathrm{PVA}+0.1 \% \mathrm{TiO}_{2}$ & 895 \\
$\mathrm{PVA}+0.2 \% \mathrm{TiO}_{2}$ & 307 \\
$\mathrm{PVA}+0.3 \% \mathrm{TiO}_{2}$ & 276 \\
$\mathrm{PVA}+0.1 \% \mathrm{ZnO}^{2}$ & 341 \\
$\mathrm{PVA}+0.2 \% \mathrm{ZnO}^{2}$ & 150 \\
$\mathrm{PVA}+0.3 \% \mathrm{ZnO}^{2}$ & 132 \\
$\mathrm{PVA}+0.1 \% \mathrm{ZrO}_{2}$ & 1190 \\
$\mathrm{PVA}+0.2 \% \mathrm{ZrO}_{2}$ & 945 \\
$\mathrm{PVA}+0.3 \% \mathrm{ZrO}_{2}$ & 823
\end{tabular}




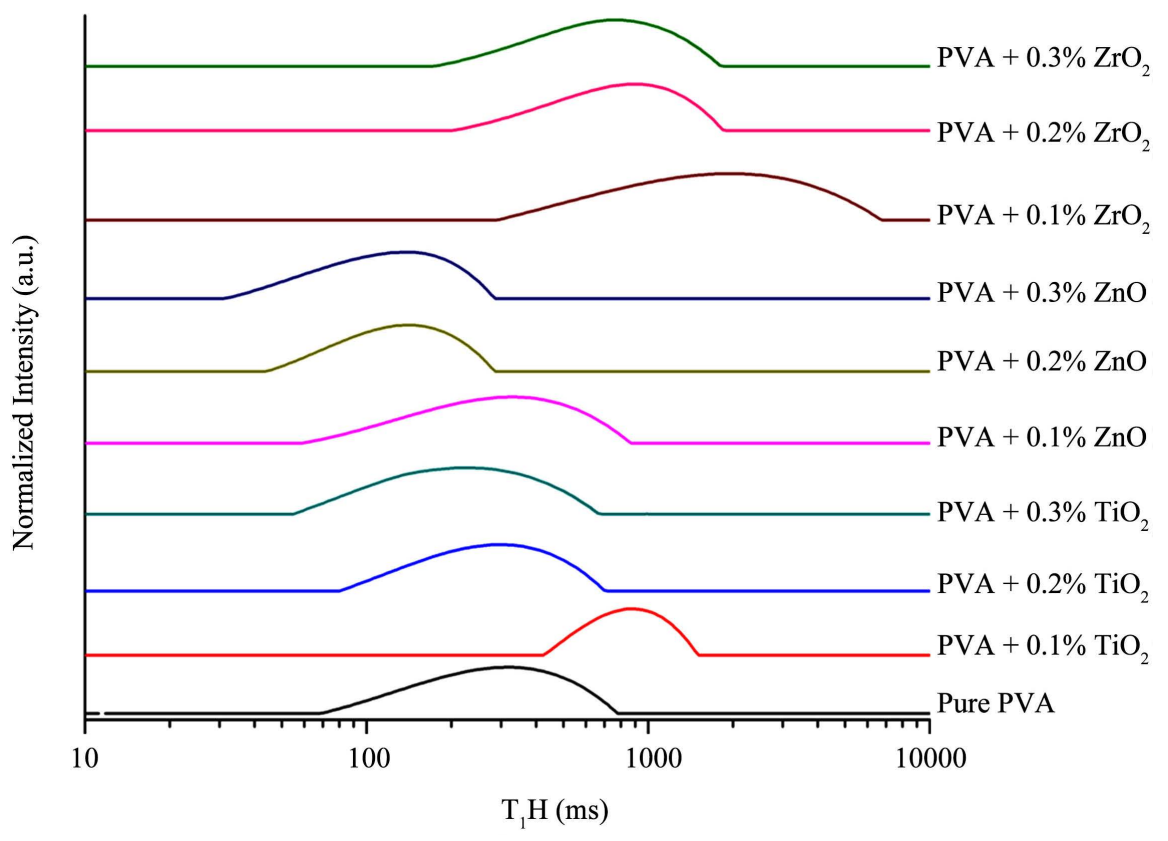

Figure 10. NMR of the PVA nanocomposites compared to the pure PVA.

Besides that, zirconia also promotes a widening of the curve, which can be attributed to two separate factors. First, it is possible that the addition of these nanoparticles may have increased not only the degree of crystallinity but also the heterogeneity of the crystals. The other possibility is that the presence of these nanoparticles may have altered the organization of the polymeric chains, creating folds, for instance, result of the high rate of interaction between PVA and zirconia.

\section{Conclusions}

The addition of the metallic oxide nanoparticles changed the thermal properties and the structure of the polymer.

The FTIR results proved that there was no chemical interaction between the components, only a physical one, between the nanoparticles and the polymeric matrix. The TGA showed no change in thermal resistance, only in the moisture uptake, due to the presence of hydrogen bonds that formed when the nanoparticles were added.

The XRD showed a change in crystalline peaks and in $\mathrm{X}_{\mathrm{c}}$ and that substantiates the DSC results. It can be noticed in these characterizations that there is an increase in crystallinity in lower concentration $(0.1 \%)$, while higher concentrations $(0.2 \%$ and $0.3 \%)$ cause a drop in $\mathrm{X}_{c}$.

These results were explained with the NMR, that showed that with lower concentration there is a better dispersion in the matrix, while the higher concentrations create clusters and a subsequent phase separation. Besides, that dispersion has an important role in the interaction between the nanoparticles and the polymer, which, in turn, influences the material's properties. 


\section{Acknowledgements}

We acknowledge IMA/UFRJ.

\section{Funding}

This work was supported by the Brazilian funding institutions CAPES and CNPQ.

\section{References}

[1] Ye, M., Mohanty, P. and Ghosh, G. (2014) Morphology and Properties of Poly Vinyl Alcohol (PVA) Scaffolds: Impact of Process Variables. Materials Science and Engineering: C, 42, 289-294. https://doi.org/10.1016/j.msec.2014.05.029

[2] Gaaz, T.S., Sulong, A.B., Akhtar, M.N., Kadhum, A.A.H., Mohamad, A.B. and Al-Amiery, A.A. (2015) Properties and Applications of Polyvinyl Alcohol, Halloysite Nanotubes and Their Nanocomposites. Molecules, 20, 22833-22847.

[3] Baker, M.I., Walsh, S.P., Schwartz, Z. and Boyan, B.D. (2012) Review A Review of Polyvinyl Alcohol and Its Uses in Cartilage and Orthopedic Applications. Journal of Biomedical Materials Research Part B: Applied Biomaterials, 5, 1-7.

[4] Ghosh, S., Sharma, A. and Talukder, G. (1992) Zirconium. An Abnormal Trace Element in Biology. Biological Trace Element Research, 35, 247-271.

[5] Liu, D., Yi, C., Zhang, D., Zhang, J. and Yang, M. (2010) Inhibition of Proliferation and Differentiation of Mesenchymal Stem Cells by Carboxylated Carbon Nanotubes. ACS Nano, 4, 2185-2195. https://doi.org/10.1021/nn901479w

[6] Costa, A.C.F.M., Vilar, M.A., Lira, H.L., Kiminami, R.H.G.A., Gama, L., Federal, U., Grande, D.C., Grande, C. and Carlos, S. (2006) Síntese e caracterização de nanopartículas de $\mathrm{TiO} 2$ (Synthesis and characterization of TiO 2 nanoparticles). Cerâmica, 52, 255-259. https://doi.org/10.1590/S0366-69132006000400007

[7] Haldorai, Y. and Shim, J. (2016) Novel Chitosan-TiO2 Nanohybrid: Preparation, Characterization, Antibacterial and Photocatalytic Properties. Polymer Composites, 25, 327-333.

[8] Y. Zhang, Nayak, T.R., Hong, H. and Cai, W. (2014) Biomedical Applications of Zinc Oxide Nanomaterials. Current Molecular Medicine, 13, 1633-1645. https://doi.org/10.2174/1566524013666131111130058

[9] Hong, H., Shi, J., Yang, Y., Zhang, Y., Engle, J.W., Nickles, R.J., Wang, X. and Cai, W. (2011) Cancer-Targeted Optical Imaging with Fluorescent Zinc Oxide Nanowires. Nano Left, 11, 3744-3750.

[10] Bunn, C.W. (1948) Crystal Structure of Polyvinyl Alcohol. Nature, 161, 929-930. https://doi.org/10.1038/161929a0

[11] Guirguis, O.W. and Moselhey, M.T.H. (2012) Thermal and Structural Studies of Poly(vinyl alcohol ) and Hydroxypropyl Cellulose Blends. Natural Science, 4, 57-67. https://doi.org/10.4236/ns.2012.41009

[12] Nasar, G., Khan, M.S. and Khalil, U. (2009) Structural Study of PVA Composites with Inorganic Salts by X-Ray Diffraction. Journal of Pakistan Materials Society, 3, 67-70.

[13] Assendert, H.E. and Windle, A.H. (1998) Crystallinity in Poly(vinyl alcohol ). 1. An X-Ray Diffraction Study of Atactic PVOH. Polymer (Guildf), 39, 4295-4302. https://doi.org/10.1016/S0032-3861(97)10296-8 
[14] Hemalatha, K.S., Rukmani, K., Suriyamurthy, N. and Nagabhushana, B.M. (2014) Synthesis, Characterization and Optical Properties of Hybrid PVA-ZnO Nanocomposite: A Composition Dependent Study. Materials Research Bulletin, 51, 438-446. https://doi.org/10.1016/j.materresbull.2013.12.055

[15] Costa, R.G.F., Ribeiro, C. and Mattoso, L.H.C. (2010) Morphological and Photocatalytic Properties of PVA/TiO2 Nanocomposite Fibers Produced by Electrospinning. Journal of Nanoscience and Nanotechnology, 10, 5144-5152. https://doi.org/10.1166/jnn.2010.2405

[16] Mansour, A.F., Mansour, S.F. and Abdo, M.A. (2015) Improvement Structural and Optical Properties of ZnO/PVA Nanocomposites. IOSR Journal of Applied Physics, 7, 60-69.

[17] Ahmad, J., Deshmukh, K. and Habib, M. (2014) Influence of $\mathrm{TiO}_{2}$ Nanoparticles on the Morphological, Thermal and Solution Properties of $\mathrm{PVA} / \mathrm{TiO}_{2}$ Nanocomposite Membranes. Arabian Journal for Science and Engineering, 39, 6805-6814.

[18] Holland, B.J. and Hay, J.N. (2001) The Thermal Degradation of Poly (vinyl alcohol). Polymer (Guildf), 42, 6775-6783. https://doi.org/10.1016/S0032-3861(01)00166-5

[19] Radoicic, M.B., Saponjic, Z.V., Marinovic-Cincovic, M.T., Ahrenkiel, S.P., Bibic, N.M. and Nedeljkovic, J.M. (2012) The Influence of Shaped $\mathrm{TiO}_{2}$ Nanofillers on the Thermal Properties of Poly (vinyl alcohol). Journal of the Serbian Chemical Society, 77, 699-714. https://doi.org/10.2298/JSC110331161R

[20] Gong, X., Yin, C., Pan, L., Hao, Z. and Pong, C. (2014) Composites: Part B Characterization of Poly (vinyl alcohol) (PVA)/ZnO Nanocomposites Prepared by a One-Pot Method. Composites Part B, 60, 144-149. https://doi.org/10.1016/j.compositesb.2013.12.045

[21] Mohanapriya, S., Mumjitha, M., Purnasai, K. and Raj, V. (2016) Fabrication and Characterization of Poly (vinyl alcohol) $-\mathrm{TiO}_{2}$ Nanocomposite Films for Orthopedic Applications. Journal of the Mechanical Behavior of Biomedical Materials, 63, 141-156.

[22] Yang, C.-C. and Lin, C.-T. (2008) Preparation of the PVA/TiO ${ }_{2}$ Nanocomposite Polymer Menbranes by a Sol-Gel Process for Alkaline DMFC. ECS Transactions, 6, 17-44. https://doi.org/10.1149/1.2927185

[23] Marras, S.I., Kladi, K.P., Tsivintzelis, I., Zuburtikudis, I. and Panayiotou, C. (2008) Biodegradable Polymer Nanocomposites: The Role of Nanoclays on the Thermomechanical Characteristics and the Electrospun Fibrous Structure. Acta Biomaterialia, 4, 756-765. https://doi.org/10.1016/j.actbio.2007.12.005

[24] Zanetti, M., Sergei, L. and Camino, G. (2000) Polymer Layered Silicate Nanocomposites. Macromolecular Materials and Engineering, 279, 1-9. https://doi.org/10.1002/1439-2054(20000601)279:1<1::AID-MAME1>3.0.CO;2-Q

[25] Silva, M.B.R., Tavares, M.I.B., Junior, A.W.M. and Neto, R.P.C. (2016) Evaluation of Intermolecular Interactions in the $\mathrm{PHB} / \mathrm{ZnO}$ Nanostructured Materials. Journal of Nanoscience and Nanotechnology, 16, 7606-7610.

[26] Soares, I.L., Chimanowsky, J.P., Luetkmeyer, L., Oliveira, E., De Holanda, D., Souza, S., Inês, M. and Tavares, B. (2015) Evaluation of the Influence of Modified $\mathrm{TiO}_{2}$ Particles on Polypropylene Composites. Journal of Nanoscience and Nanotechnology, 15, 5723-5732. https://doi.org/10.1166/jnn.2015.10041 